\title{
Modelling of sequencing batch reactor operating at various aeration modes
}

\author{
Grzegorz Łagód ${ }^{1 *}$, Adam Piotrowicz ${ }^{1}$, Piotr Gleń ${ }^{2}$, Jakub Drewnowski ${ }^{3}$, and Fabrizio Sabba ${ }^{4}$ \\ ${ }^{1}$ Lublin University of Technology, Faculty of Environmental Engineering, Nadbystrzycka 40B, 20-618 Lublin, Poland \\ ${ }^{2}$ Lublin University of Technology, Faculty of Civil Engineering and Architecture, Nadbystrzycka 40, 20-618 Lublin, Poland \\ ${ }^{3}$ Gdansk University of Technology, Faculty of Civil and Environmental Engineering, Narutowicza 11/12, 80-233 Gdansk, Poland \\ ${ }^{4}$ Northwestern University, Department of Civil and Environmental Engineering, Evanston, Illinois 60208, United States
}

\begin{abstract}
The presented study involved designing a computer model of a sequencing batch reactor (SBR) at laboratory scale. The data pertaining to the technical aspects of the bioreactor and quality indicators of wastewater constituted the input for the employed simulation tool, i.e. GPS-X software package. The results of a simulation involving a 12-hour operation cycle are presented in this work; each cycle included 6 phases: filling, mixing, aeration, settling, decantation and idling (wasting of excess sludge). The simulations were carried out using two different modes of aeration. Concentration of dissolved oxygen (DO) was maintained at constant level of $2 \mathrm{mgO} / \mathrm{L}$ using the PID controller in the first case. On the other hand, variation of DO concentration was employed in the aeration stage of the second variant, which was achieved using appropriately elaborated set point of oxygen concentration, considering the specific intervals in oxygen supply. The changes observed in DO concentration varied from 0.5 to $2.5 \mathrm{mgO}_{2} / \mathrm{L}$. This research proved that the second variant, involving variation of DO concentration, was characterised by reduced levels of pollution indicators in treated sewage, as well as lower consumption of electricity, both of which contributed towards improving the effluent quality and resulted in significant degree of dephosphatation.
\end{abstract}

\section{Introduction}

Computer software that allows for modelling of the existing wastewater treatment systems is becoming more frequently used for examining the prospective results of modernisations. These programs enable to test different solutions before they are introduced, thus avoiding the least efficient or defective options. The removal of biogenic compounds is crucial from the point of view of environmental protection, and it necessitates appropriate operation of each device in the wastewater treatment plant (WWTP). Stability of the system is susceptible to even minor changes in the process conditions. Therefore, the selection of suitable solutions, yielding the most favourable outcomes at lowest financial outlays, constitutes a significant advantage of applying simulation software. This software enables also to verify the correct operation of a system with no need of constructing pilot plants. Additionally, using abovementioned software, it is possible to design a few alternatives and select the best one, e.g. in terms of the cost or environmental impact.

Currently, specialist simulation tools and computer modelling software are a key factor for planning technological changes in WWTPs. It is argued that in the future, the operation of each WWTP will depend on them [1-5]. They enable to gain insights for devices that undergo dynamic changes; thus, the limits and static values taken into account at the designing stage are significantly expanded. Application of mathematical models by WWTPs operators is possible via specialised software, such as GPS-X, SIMBA, STOAT, BioWin and WEST etc. [6]. The first one constitutes a dedicated simulation software, developed by Hydromantis Environmental Software Solutions that aims at carrying out simulations for both municipal as well as industrial wastewater treatment processes, with the flexibility of utilising different devices. This software, depending on the needs of a user, also enables to employ various process models, including mechanical parts of the plant, biological components with continuous flow and batch bioreactors, as well as sludge disposal systems.

Batch reactors, which also comprise Sequencing Batch Reactors (SBRs), represent a type of bioreactors used for removal of nitrogen, phosphorus and carbon compounds from the wastewater subjected to treatment under aerobic and anaerobic conditions. A major difference between treating wastewater in a continuous flow system and a batch reactor is that in the latter the processes are carried out in a single chamber, which simultaneously functions as a reaction chamber and a secondary settling tank. The operation of SBR includes cyclic change of phases that occur in a sequence. Most often, 2-4 cycles are performed daily [7-13]. Treating wastewater in SBRs is highly advantageous, as it enables to control the aerobic conditions that are prone to

*Corresponding author: g.lagod@ pollub.pl 
changes over time. It also allows adjusting the length and order of individual phases [14-19]. The basic operation phases in SBRs are as follows: filling, mixing, aeration, settling, decantation, idling [20-23].

SBRs can be successfully used in the settlement units with either low or highly time-variable wastewater flow. Moreover, they are employed in combined systems that enable the pre-treatment or treatment of medical and pharmaceutical, toxic or recalcitrant wastewater. On the other hand, conducting research and implementing new measurement methods, technological solutions or exploitation strategies can be greatly supported by appropriately smaller bioreactors, constructed at laboratory scale $[14,24-34]$. This is because smaller dimensions of the chamber enable for the simulation of different sludge operation conditions, as well as various length of cycles or individual phases.

The presented research aimed at simulation of the processes in the SBR, which removed nutrients under diversified aeration conditions. The computer model simulating the operation of the SBR was presented in the work, along with the results obtained from the simulation of municipal wastewater treatment processes. The influence of two different aeration modes - constant oxygen level of $2.0 \mathrm{mg} / \mathrm{L}$, and varied oxygen concentrations was assessed using the results of computer simulations.

\section{Materials and methods}

\subsection{Modelled object}

Creating a computer model enabled carrying out the simulations for an SBR that operated at a laboratory scale and was characterised by the active volume of $8 \mathrm{~L}$ (total volume of $10 \mathrm{~L}$ ), as well as influent/effluent volume of $2.5 \mathrm{~L}$ [30]. Prior to the experiments, a start-up of the reactor was performed, resulting in initial lowered treatment efficiency. However, the system regained stability afterwards, and the quality of effluent was improved. Simulating the standard conditions of SBR operation at laboratory scale was the first stage of the conducted research. The parameters determined using the results obtained from laboratory measurements were employed in the simulation. Table 1 presents the influent parameters used as input for the model.

The following stage of the research involved implementing modifications that improved the removal of biogenic compounds. In accordance with the literature data, appropriate settings of the operation cycle, and process conditions in the reactor enable to achieve relatively low concentration of phosphorus, without chemical precipitation. This is because the removal of biogenic compounds is governed by the aerobic-anaerobic conditions [35]. Modification of the experiment consisted in the introduction of certain intervals in the supply of compressed air during the aeration phase. Concentration of dissolved oxygen (DO) in the reaction chamber was altered by turning the aeration valve on and off.

The considered system comprised the following objects: Influent, Advanced SBR, Equalization tank and Effluent (Fig. 1). Activated sludge process was modelled with the use of ASM2d model. Simulation of the carbon, nitrogen, and phosphorus transformation processes was carried out using the Carbon-Nitrogen-Phosphorus library (CNPlib).

Table 1. Influent data used in model.

\begin{tabular}{|c|c|c|}
\hline Parameters & Value & Unit \\
\hline COD & 766 & $\mathrm{mg} / \mathrm{L}$ \\
\hline $\mathrm{BOD}_{5}$ & 435 & $\mathrm{mg} / \mathrm{L}$ \\
\hline TSS & 319 & $\mathrm{mg} / \mathrm{L}$ \\
\hline Total nitrogen & 107 & $\mathrm{mg} / \mathrm{L}$ \\
\hline TKN & 105 & $\mathrm{mg} / \mathrm{L}$ \\
\hline Total phosphorus & 18.0 & $\mathrm{mg} / \mathrm{L}$ \\
\hline Ortho-phosphate & 13.7 & $\mathrm{mg} / \mathrm{L}$ \\
\hline Nitrate and nitrite & 1.9 & $\mathrm{mg} / \mathrm{L}$ \\
\hline Ammonia & 85 & $\mathrm{mg} / \mathrm{L}$ \\
\hline XCOD/VSS (icv) & 1.95 & $\mathrm{mgCOD} / \mathrm{mgVSS}$ \\
\hline $\mathrm{BOD}_{5} / \mathrm{BOD}_{\text {ultimate }}(f b o d)$ & 0.65 & - \\
\hline $\mathrm{VSS} / \mathrm{TSS}(i v t)$ & 0.8 & $\mathrm{mgVSS} / \mathrm{mgTSS}$ \\
\hline $\operatorname{COD}_{\text {Soluble }}($ frscod $)$ & 0.35 & - \\
\hline $\mathrm{COD}_{\text {Inert }}(f r s i)$ & 0.15 & - \\
\hline COD $_{\text {Soluble VFA }}(f r s l f)$ & 0.18 & - \\
\hline $\mathrm{COD}_{\text {Substrate }}($ frxs $)$ & 0.8 & - \\
\hline $\mathrm{COD}_{\text {нв }}(f r x b h)$ & 0.06 & - \\
\hline $\mathrm{COD}_{\mathrm{AB}}(f r x b a)$ & 0.01 & - \\
\hline CODPoly-P в $(f r x b p)$ & 0.01 & - \\
\hline $\mathrm{COD}_{\text {PHA }}(f r x b t)$ & 0 & - \\
\hline $\begin{array}{l}\text { Phosphorus Soluble Ortho-p } \\
\text { (frsp) }\end{array}$ & 0.9 & - \\
\hline $\begin{array}{l}\text { Phosphorus Particulate xpp } \\
\text { (frxpp) }\end{array}$ & 0 & - \\
\hline TKN $_{\text {Ammonium }}($ frsnh $)$ & 0.95 & - \\
\hline
\end{tabular}

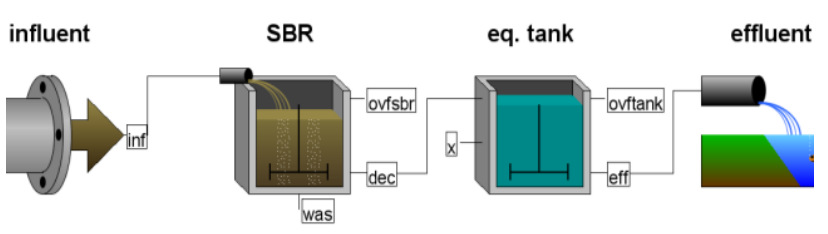

Fig. 1. Elements of the modelled system with labels of stream: inf - influent, ovfs $b r$ - SBR overflow, dec-SBR outflow, ovftank - tank overflow, eff-effluent, was - excessive sludge, $x$ - unused.

Two cycles (12 hours each) were carried out daily in the model experiments. The length and types of particular phases were in employed accordance with the operation cycle of laboratory scale SBRs. Each cycle involved the following six phases: I - filling ( $30 \mathrm{~min})$, II - mixing (120 min), III - aeration (420 min), IV settling (90 min), V - decantation (50 min), and VI idling (removal of excessive sludge $-10 \mathrm{~min}$ ). The analysis of system operating under laboratory conditions constituted the basis for the simulation (it was assumed that concentrations of quality indicators contained in the influent in each operation cycle were unchanged).

\subsection{Simulation scenarios}

Two variants of simulations, differing in respect to the aeration method, were employed for the considered model, each lasting for 20 cycles (10 days). The first 
variant represents the standard system. The reactor was aerated for 420 minutes with a fixed oxygen content $(2$ $\mathrm{mgO}_{2} / \mathrm{L}$ ), which was maintained using a PID controller that allowed for automatic regulation of the introduced stream of air. In the other case, the second variant involved implementation of intervals during the aeration, resulting in diversification of DO content, ranging from 0.5 to $2.5 \mathrm{mgO}_{2} / \mathrm{L}$. A data file fed to the simulation program enabled to adjust the DO setpoint during aeration. Thus, scheduled intervals of compressed air supply to the bioreactor chamber were introduced. This enabled to regulate the concentration of DO and maintain it above the level of $0.5 \mathrm{mgO}_{2} / \mathrm{L}$ at the end of each interval of aeration, thus meeting the assumed requirements.

\section{Results and discussion}

SBRs are characterised by the variability of processes in treatment cycles. Taking this factor into account, each simulation involved 20 cycles. The concentration profiles of COD, BOD 5 , TSS (Fig.2), nitrogen compounds including ammonia, nitrate and nitrite, TKN and TN (Fig.3) and phosphorus compounds, measured as ortho-phosphate and total phosphorus (Fig.4), were analysed in both simulation variants.

In the first simulation variant (constant aeration), $\mathrm{COD}, \mathrm{BOD}_{5}$ and TSS reached the concentrations of 57.2, 6.7 and $16.9 \mathrm{mg} / \mathrm{L}$, respectively. The concentration of nitrogen compounds i.e. nitrate and nitrite, ammonia, TKN and total nitrogen, amounted to 27.3, 1.9, 3.2 and $30.4 \mathrm{mg} / \mathrm{L}$, respectively.
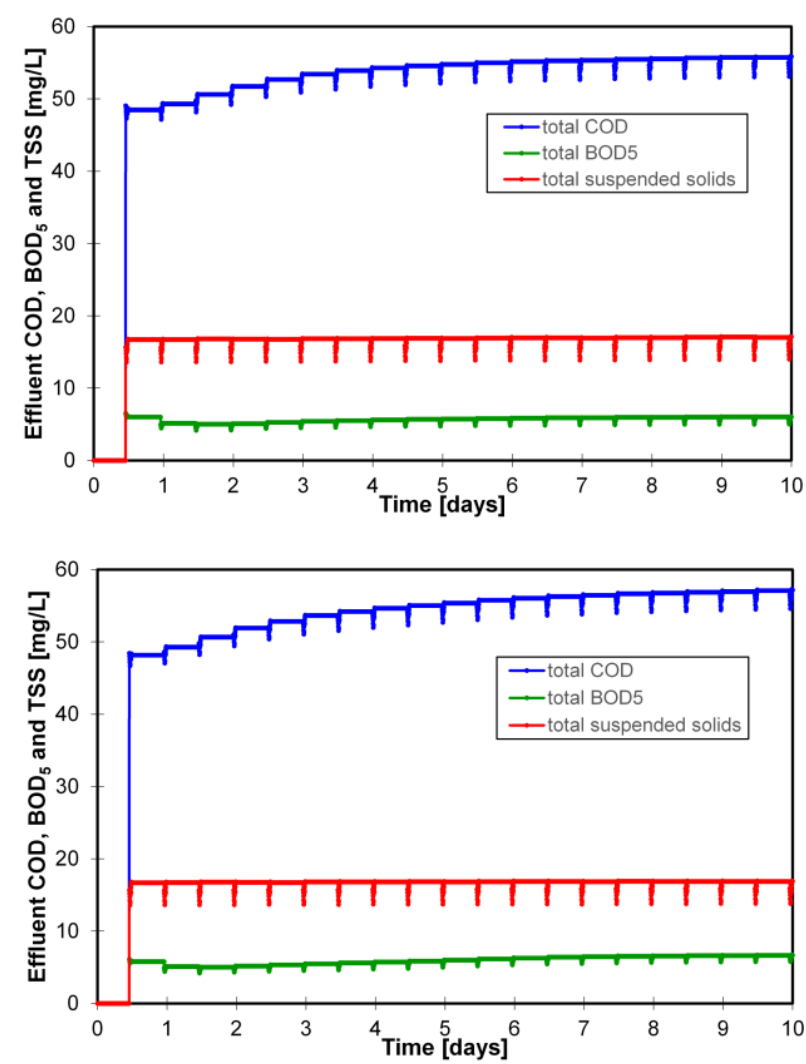

Fig. 2. Effluent levels of COD, BOD 5 and TSS obtained for aeration with DO at constant level (upper) and with intervals (lower).
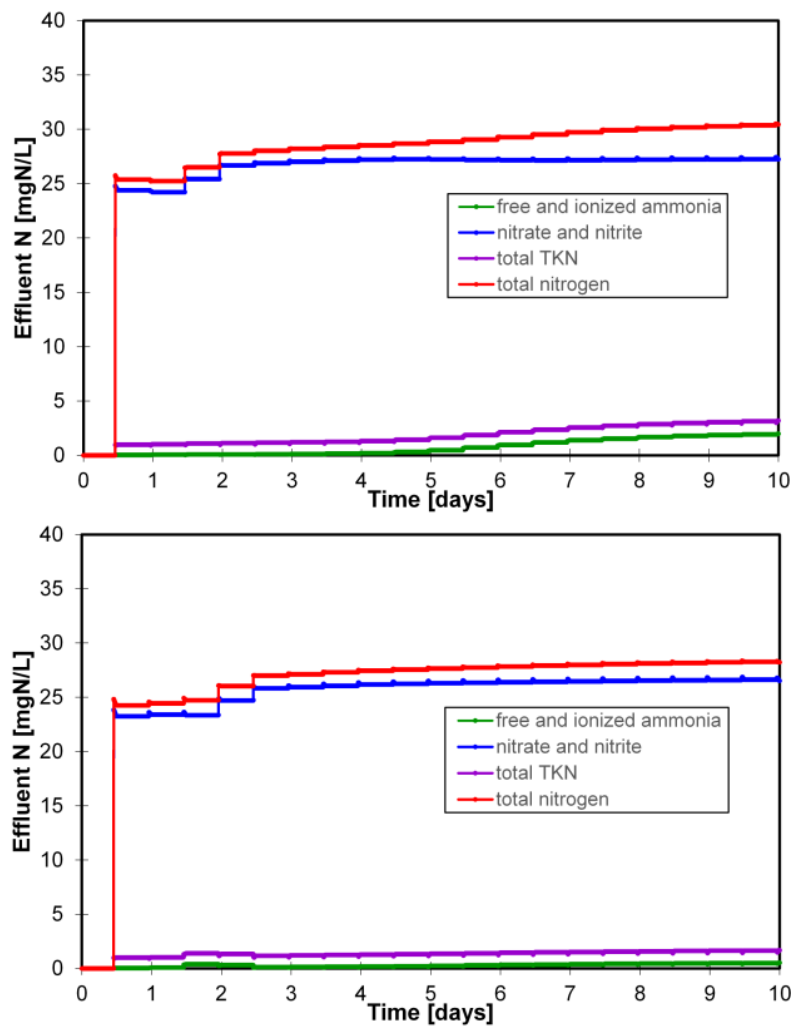

Fig. 3. Effluent levels of nitrogen compound indicators obtained for aeration with DO at constant level (upper) and with intervals (lower).
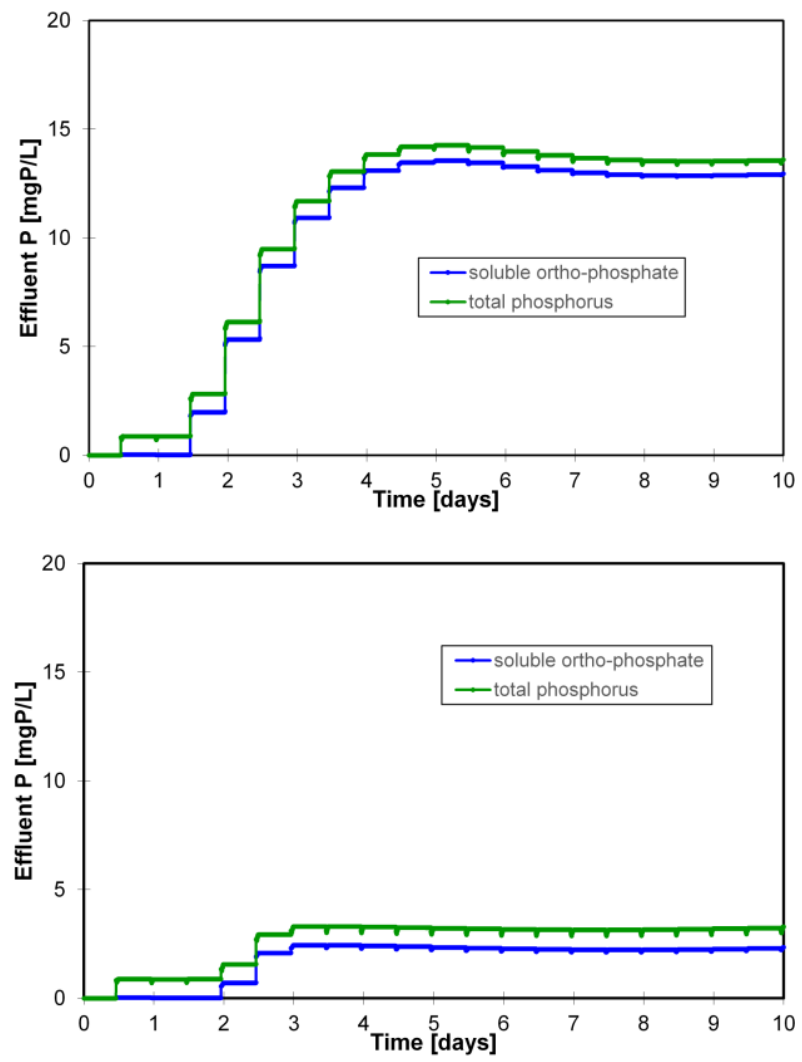

Fig. 4. Effluent levels of phosphorus compound indicators obtained for aeration with DO at constant level (upper) and with intervals (lower). 
On the other hand, the concentrations of soluble ortho-phosphates and total phosphorus reached 12.9 and $13.6 \mathrm{mg} / \mathrm{L}$, respectively. Although the achieved quality of effluent was unsatisfactory, especially considering the values of phosphorus compounds, it depicted the conditions characterising a standard operating system.

In the other variant, involving aeration intervals, the values of $\mathrm{COD}, \mathrm{BOD}_{5}$ and TSS concentrations equalled $55.8,6.0$ and $17.1 \mathrm{mg} / \mathrm{L}$, respectively. The compounds of nitrogen, including nitrate and nitrite, ammonia, TKN as well as total nitrogen amounted to $26.5 \mathrm{mg} / \mathrm{L}, 0.5 \mathrm{mg} / \mathrm{L}$, $1.7 \mathrm{mg} / \mathrm{L}$, and $28.2 \mathrm{mg} / \mathrm{L}$, respectively. On the other hand, the soluble ortho-phosphate and total phosphorus corresponded to 2.3 and $3.3 \mathrm{mg} / \mathrm{L}$, respectively.

Following a 10-day simulation, the depicted concentration profiles were characterised by a relative stability. However, the comparison of both variants showed the greater efficiency of the second one, particularly in respect to the concentration of phosphorus and to a lesser extent, nitrogen. In the case of phosphorus, the efficiency was greater by almost 58 p.p. As far as COD, $\mathrm{BOD}_{5}$, and TSS are concerned, the resulting concentrations were similar, but nevertheless slightly better for the second variant.
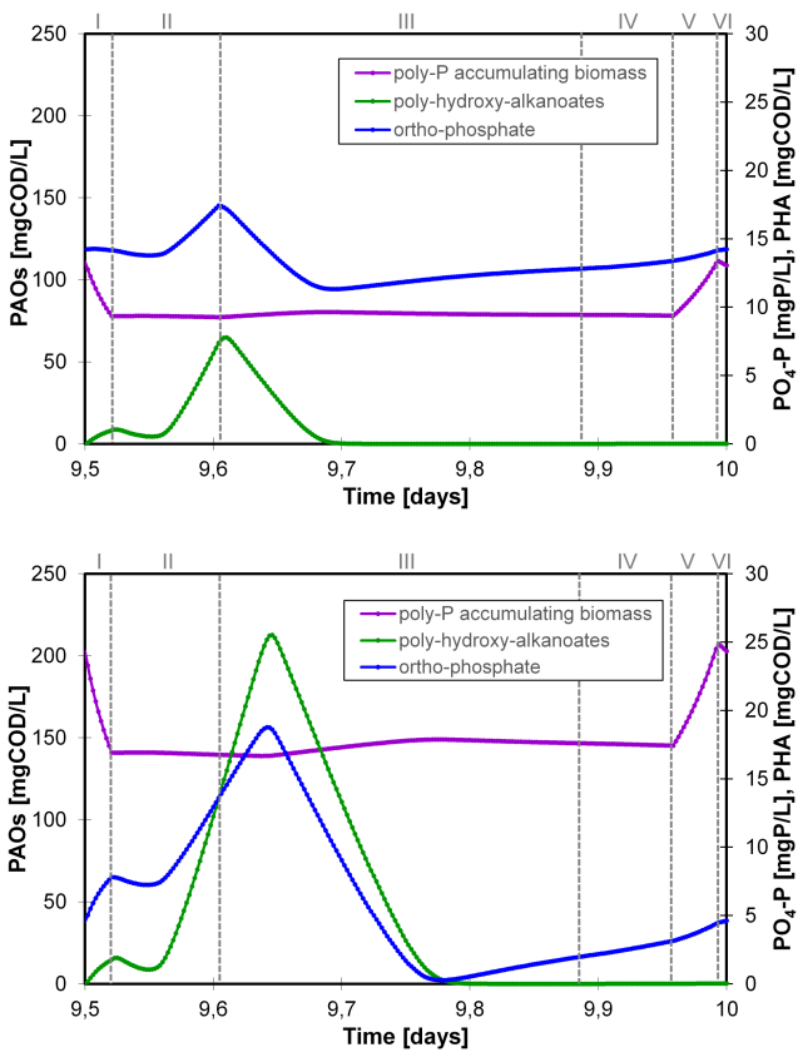

Fig. 5. Concentration profiles of ortho-phosphate, polyhydroxy-alkanoates and active PAO biomass obtained for aeration with DO at constant level (upper) and with intervals (lower).

The most significant results obtained in the course of simulations pertained to the removal of phosphorus; hence, more relevant data connected with this finding should be considered. Because the simulation was conducted for 20 cycles, it would be inconvenient to present the changes occurring in particular phases on a single graph. For this reason, the graphs that compared the both variants were prepared for the last day of the simulation, i.e. 1 cycle and shown in Figure 5. Three state variables related to dephosphatation are presented: soluble ortho-phosphates, active poly-P accumulating microorganism biomass (PAOs) and poly-hydroxyalkanoates (PHAs), along with phase identifier. The second variant of the simulation exhibited a favourable influence on the increase of PAOs, contributing to a greater efficiency of PHAs storage as well as improved uptake of soluble ortho-phosphate during the aeration phase.

Table 2 shows all the important indicators, including the influent and effluent of the reactor chamber. Additionally, the comparison of both considered simulation variants was carried out by calculating the treatment efficiency based on the concentrations characterising the influent and effluent.

Table 2. Effluent quality for both simulated variants expressed as concentration and efficiency.

\begin{tabular}{|c|c|c|}
\hline \multirow{2}{*}{ Indicator } & Variant I & Variant II \\
\cline { 2 - 3 } & $\mathrm{mg} / \mathrm{L} \mathrm{( \% )}$ & $\mathrm{mg} / \mathrm{L}(\%)$ \\
\hline Ammonia nitrogen & $1.9(97.7)$ & $0.5(99.4)$ \\
\hline TKN & $3.2(97.0)$ & $1.7(98.4)$ \\
\hline Total nitrogen & $30.4(71.6)$ & $28.2(73.6)$ \\
\hline Total phosphorus & $13.6(24.5)$ & $3.3(81.7)$ \\
\hline Orthophosphate & $12.9(5.5)$ & $2.3(82.9)$ \\
\hline COD & $57.2(92.5)$ & $55.8(92.7)$ \\
\hline BOD $_{5}$ & $6.7(98.5)$ & $6.0(98.6)$ \\
\hline TSS & $16.9(94.7)$ & $17.1(94.6)$ \\
\hline
\end{tabular}

The biological treatment of wastewater involves the microorganisms that remove pollutants by taking part in various processes, including nitrification, denitrification, mineralisation and biological dephosphatation. High concentration of $\mathrm{TN}$ in both simulation variants resulted from inefficient denitrification under anoxic conditions of the activated sludge operation. This, in turn, was caused by highly efficient oxidation of ammonia nitrogen to nitrate, along with a low reduction of nitrates to molecular nitrogen.

\section{Conclusion}

The results of computer simulations obtained in this study were employed for evaluating the impact of two aeration modes, i.e. with a constant oxygen level of 2.0 $\mathrm{mg} / \mathrm{L}$ as well as variable oxygen concentrations. The simulation involved the concentration profiles of several quality indicators, including $\mathrm{COD}, \mathrm{BOD}_{5}$, TSS, nitrogen compounds (with ammonia, nitrate and nitrite, TKN and $\mathrm{TN}$ ) and phosphorus compounds, measured as orthophosphate as well as total phosphorus.

This research indicated that the second variant, involving changes of DO concentrations during the aeration phase was more successful in removing the biogenic compounds. The removal of total phosphorus and orthophosphates improved from $24.5 \%$ to $81.7 \%$ and from $5.5 \%$ to $82.9 \%$, respectively. On the other hand, the efficiencies of $\mathrm{COD}, \mathrm{BOD}_{5}$ and TSS removal were 
similar; however, the second variant exhibited a slightly higher efficiency in the removal of COD and BOD5, and lower efficiency for the removal of TSS. Additionally, the second variant was characterised by greater energy efficiency, because less power was used as a result of intervals in the aeration phase.

Because only a single factor was considered in the simulation comparing the two variants, it can be stated that the higher effluent quality obtained in the second variant is the outcome of implementing intervals in the introduction of compressed air during the aeration phase that diversifies DO concentrations as a result.

\section{References}

1. D.J. Dürrenmatt, W. Gujer, Environ. Model. Softw. 30, 47-56, (2012)

2. G. Mannina, A. Cosenza, G. Viviani, Phys. Chem. Earth, 42-44, 61-69 (2012)

3. A. Cosenza, G. Mannina, P.A. Vanrolleghem, M.B. Neumann, Environ. Modell. Softw. 49, 40-52 (2013)

4. A. Kusiak, Y. Zeng, Z. Zhang, Eng. Appl. Artif. Intel. 26,1643-1651 (2013)

5. M. Pomiès, J.M. Choubert, C. Wisniewski, M. Coquery, Sci. Total Environ. 443, 733-748 (2013)

6. R. Barat, T. Montoya, A. Seco, J. Ferrer, Water Res. 45, 3744-3752 (2011)

7. E. Belia, P.G. Smith, Water Sci. Technol. 35(1), 1926 (1997)

8. C-H. Yoon, H-J. Yang, J-B. Seo, Y-T. Rim, J-R. Ryu, E-B. Shin, Water Sci. Technol. 35 (1), 241-247 (1997)

9. I. Shizas, D.M. Bagley, Water Res. 36, 363-367 (2002)

10. Y.J. Chan, C.M. Fong, C.L. Law, J. Environ. Manage. 91, 8, 1738-1746 (2010)

11. A. Cydzik-Kwiatkowska, M.Zielińska, K. Bernat, I. Wojnowska-Baryła, New Biotech. 29, S183 (2012)

12. S. Lackner, H. Horn, Bioresour. Technol. 107, 70-77 (2012)

13. J. Bai, H. Xu, Y. Zhang, Z. Peng, G. Xu, Biochem. Eng. J. 70, 115-119 (2013)

14. D.A. Irvine, J.P. Earley, D.P. Cassidy, S.P. Harvey, Water Sci. Technol. 35, 1, 67-74 (1997)

15. S. Mace, J. Mata-Alvarez, Ind. Eng. Chem. Res. 41, 5539-5553 (2002)
16. N. Artan, D. Orhon, Mechanisms and design of sequencing batch reactors for nutrient removal (IWA Publishers, London, 2005).

17. A.H. Mahvi, Iran. J. Environ. Health Sci. Eng. 5, 2,79-90 (2008)

18. Y.J. Chan, M.F. Chong, C.L Law,. D.G. Hassell, Chem. Eng. J. 155, 1-18 (2009)

19. L. Luccarini, G.L. Bragadin, G. Colombini, M. Mancini, P. Mello, M. Montali, D. Sottara, Environ. Modell. Softw. 25, 648-660 (2010)

20. EPA 625/R00/008, Onsite Wastewater Treatment Systems Manual: Sequencing Batch Reactor Systems (U.S. Environmental Protection Agency, 2002)

21. R. Babko, T. Kuzmina, K. Jaromin-Gleń, A. Bieganowski, Ecol. Chem. Eng. S 21, 4, 605-616 (2014)

22. R. Babko, K. Jaromin-Gleń, G. Łagód, M. Pawłowska, A. Pawłowski, Des. Water Treat. 57, 3, 1490-1498 (2016)

23. A. Szaja, G. Łagód, K. Jaromin-Gleń, A. Montusiewicz, Water 10, 5 (2018)

24. J. Malicki, A. Montusiewicz, A. Bieganowski, Water Res. 35/9, 2333-2335 (2001)

25. E. Neczaj, M. Kacprzak, J. Lach, E. Okoniewska, Desalination 204, 227-233 (2007)

26. E.S. Elmolla, M. Chaudhuri, Desalination, 285, 1421 (2012)

27. X. Quan, M. Zhang, P.G. Lawlor, Z. Yang, X. Zhan, Water Res. 46, 4981-4990 (2012)

28. C. Li, S. Liang, J. Zhang, H.H. Ngo, W. Guo, N. Zheng, Y. Zou, Chem. Eng. J. 222, 353-360 (2013)

29. M. Zubrowska-Sudol, J. Walczak, Water Res. 61, 200-209 (2014)

30. Ł. Guz, G. Łagód, K. Jaromin-Gleń, Z. Suchorab, H. Sobczuk, A. Bieganowski, Sensors. 15, 1-21 (2015)

31. K. Sytek-Szmeichel, J. Podedworna, M. ZubrowskaSudol, Water Sci. Technol. 73, 6, 1349-1356 (2016)

32. E. Lobos-Moysa, M. Dudziak, M. Bodzek, Ochr. Sr. 32, 2, 53-56 (2010)

33. S. Waclawek, K. Grubel, Z. Chlad, M. Dudziak, M. Cernik, Water Environ. Res. 88(2), 152-157 (2016)

34. S. Werle, M. Dudziak, K. Grubel, J. Environ. Sci. Health Part A-Toxic/Hazard. Subst. Environ. Eng. 51(9), 754-758 (2016)

35. K. Piaskowski, Rocz. Ochr. Środ. 5, 221-237 (2003) 